\title{
Comparison of Removal Effectiveness of Mixed versus Displacement Ventilation during Vacuuming Session
}

\author{
C. Habchi ${ }^{1}$, K. Ghali ${ }^{2}$ and N. Ghaddar ${ }^{2}$ \\ ${ }^{1}$ Mechanical Engineering Department, Faculty of Engineering, Lebanese University, Branch II, Roumieh, Lebanon \\ ${ }^{2}$ Department of Mechanical Engineering \\ American University of Beirut \\ P.O. Box 11-0236, Beirut 1107-2020, Lebanon \\ Phone/Fax number: +961 1 340460, Ext.3438, e-mail: ka04@aub.edu.lb
}

\begin{abstract}
In indoor environments, floor surfaces are sinks of particles that might re-suspend in air. If not removed by the ventilation configuration, particles carrying bacteria and viruses constitute a threat for occupant's health. Selecting a proper ventilation system with convenient design parameters plays an important role in particle removal from the occupied space. In this work, a typical office space was considered with the option of varying the ventilation configuration by considering a mixing ventilation (MV) system, displacement ventilation (DV) system, and reversed displacement ventilation (RDV) system. The effectiveness of these systems in removing resuspended particles from the indoor space during vacuuming sessions was studied. For this reason, a transient 3D computational fluid dynamics (CFD) model was developed and was validated experimentally in a climatic chamber equipped with both $\mathrm{MV}$ and DV systems. Good agreement was obtained between measured and predicted values of particles' concentration with low relative error in the order of $10 \%$. The parametric study conducted showed that the reversed DV configuration insured the best particle removal performance by resulting in an effective suction effect at the floor level. The worst performance was provided by the conventional DV system due to the upward DV airflow transporting the resuspended particles from the floor levels to the upper breathing levels spreading contaminants. From here the RDV configuration was suggested for operation of ventilation system during vacuuming session to enhance particle removal.
\end{abstract}

\section{Key words}

Mixing and displacement ventilation, reversed displacement ventilation, particle removal efficiency, air flow rate, escaped particles.

\section{Introduction}

Floor surfaces constitute reservoirs of particles that can re-suspend in indoor air [1]. Re-suspended particles can carry viruses and bacteria representing a significant risk of occupants' infection [2]. Deposited particles can originate from variable outdoor and indoor sources and vary in diameter from nanometers to millimeters [3]. Particle re-suspension can result from variable processes as flow disturbances, mechanical activities as babies crawling and human motion [4-6]. Dusting and vacuuming have been also identified to cause resuspension in indoor environments [7-8].

Floor vacuuming is frequently used as a mechanism to remove indoor particles. However, it was not found to be a very effective cleaning process [9]. For instance, vacuuming has been identified to be a significant source of airborne particulate matter, with an average dust removal efficiency of $50 \%-60 \%$ [9] for a typical household vacuum cleaner. Several researchers observed elevated concentrations of dust particles in air during and shortly after vacuuming activities in indoor spaces $[8$, 10]. In fact, the floor constitutes a large reservoir for dust and contagious particles requiring frequent cleaning by vacuuming. Unfortunately, only a portion will be taken by the vacuuming machine while the other portion will be suspended into the space air volume. Depending on the air distribution system and the size of the particles, these particles might stay a long time in the space air before settling again into the floor or being escaped by the air distribution system $[11,12]$. Therefore, assisting vacuuming by proper airflow distribution is important to enhance the removal efficiency. In fact, if not removed, suspended particles that may carry viruses and bacteria represent high risk of contaminating occupants. This threat to human health can be decreased by controlling the airflow pattern during vacuuming. Since the ventilation system plays a major role in particle distribution and removal from the occupied space [13, 
14], the heating ventilation and air conditioning (HVAC) during the vacuuming session should be carefully selected.

Two conventional air conditioning systems are the mixed ventilation (MV) system where the supply and return air outlets are located at the ceiling level [15] and displacement ventilation (DV) where the air distribution is turned upside down by supplying fresh air near the floor level [16, 17]. Removal of floor generated particles by these conventional HVAC methods is limited by gravitational settling opposing upward particle motion to reach the exhaust vents $[18,19]$. For instance, Brohus and Nielson [19] observed that DV was ineffective in protecting occupant when particles were generated at low level and presented higher exposure than conventional MV. Furthermore, Habchi et al. [20] observed that in a DV system, particles might be caught below the stratification zone because of the two opposing effects of the upward momentum flow and the downward gravitational settling.

The aim of this study is to compare MV and DV air distribution systems in terms of their effectiveness in removing re-suspended particles from the indoor space. Since vacuuming constitutes one of the main sources of particle re-suspension indoors, recommendations will be provided for the operation of ventilation systems during vacuuming session for improved particle removal. Simulation of airflow pattern and particles' distribution involves complex physics requiring appropriate modeling [21]. For this reason ANSYS Fluent was used to develop a computational fluid dynamics (CFD) model and validation was performed by conducting experiments. The validated CFD model was then adopted to perform a parametric study on spaces ventilated by MV and DV systems to assess their effectiveness in particle removal during a vacuuming session.

\section{Problem description}

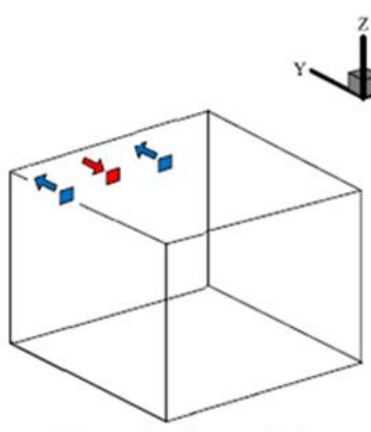

(a) ventilation mode 1

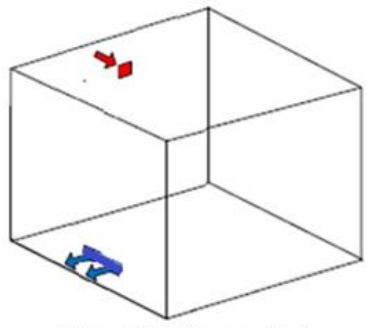

(c) ventilation mode 3

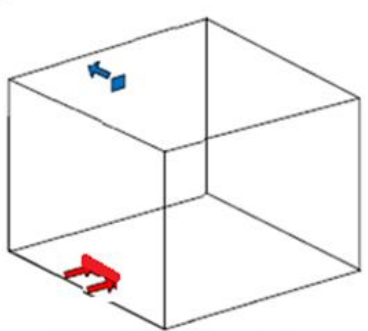

(b) ventilation mode 2

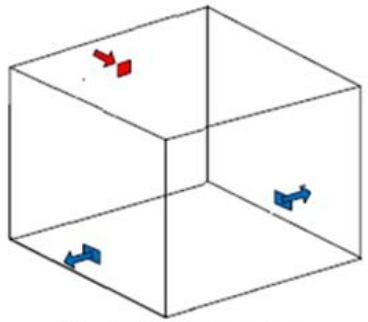

(d) ventilation mode 4
Fig. 1. Different ventilation modes studied.
All MV configurations investigated shared the inlet vent location at top north wall but differed by the placement level of the outlet. Exhaust location is expected to largely affect particle behavior since it modifies the airflow circulation pattern.

Inlet and outlet vents are commonly placed at the ceiling level for MV while for DV air is supplied at low level and exhausted at ceiling level. An unconventional relative inlet/outlet location is reversed DV configuration where supply is from ceiling and return is at floor level. The focus of this study is to compare effectiveness in particle removal during vacuuming session for these configurations.

The different configurations shown in Fig. 1 are described below:

a) Ventilation mode 1: Conventional MV configuration with top supply and top return vents

b) Ventilation mode 2: DV configuration with one floor supply and top return vent

c) Ventilation mode 3: Reversed DV (RDV1) configuration with one floor register and top supply vent d) Ventilation mode 4: RDV2 configuration with two floor registers and top supply vent

\section{CFD Modeling}

To simulate re-suspended particles behavior for different ventilation configurations, numerical CFD simulations of an indoor space were conducted with particle generation at floor level.

The commercial software ANSYS Fluent was adopted to compute the flow, thermal, and concentration fields within the indoor environment. The Eulerian approach was used to simulate the room air since it can be considered as a continuous fluid [22]. The interaction between particle and fluid phases was considered as one way coupling neglecting the effect of particles on the airflow field since the discrete phase volume is negligible compared to the room volume [23]. ANSYS Fluent offers different schemes for discretization of the Navier-Stokes equations. The "PRESTO!" staggered scheme was selected for the pressure while the SIMPLE algorithm was adopted for coupling of the velocity and pressure fields [24].

Turbulence and buoyancy largely affect the airflow pattern $[25,26]$ and should be accurately modeled. The realizable $\mathrm{k}-\varepsilon$ model was selected to model turbulence effect with enhanced wall treatment [23]. To trap buoyancy effects the incompressible ideal gas law was adopted [23]. The second-order upwind scheme was used for discretization of the dissipation rate, the turbulence kinetic energy, and the momentum equations.

The Lagrangian tracking method was used to simulate particle behavior in indoor spaces and calculate concentration field using the second law of Newton by tracking several particles trajectories within the enclosed room [24, 27]. The influencing forces on behavior of particles were considered. These forces are correlated to particle characteristics (as density, shape, and size). The 
drag force is the dominant force on particle distribution [27]. Nevertheless, at the proximity of walls within the turbulent boundary layer, Brownian and Saffman's lift forces play an important role in particle behavior and deposition and should be considered [28].

The discrete random walk model (DRW) was selected to model the effect of local turbulence intensities on particles' paths by using a stochastic approach [29]. The particle source in-cell (PSI-C) scheme was adopted to correlate particle trajectories and particle concentration within each computational cell.

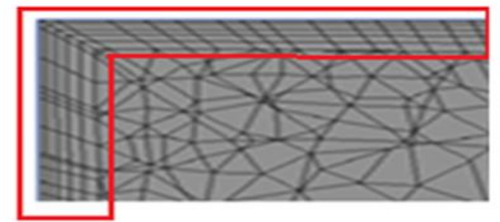

Surface Inflation

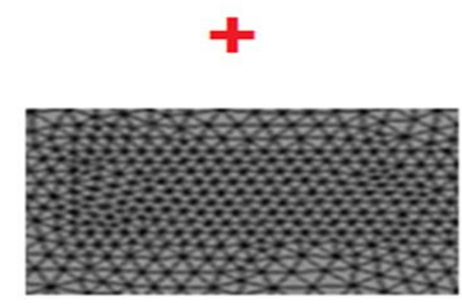

Face Sizing

Fig. 2. CFD mesh treatment.

Appropriate boundary conditions are required for precise computation of particle comportment. For instance, the "escape" boundary condition was designated at outlets while the "trap" condition was used to consider particle deposition in case a particle trajectory reached a wall [30].

The CFD model mesh was generated using tetrahedral unstructured grid as represented in Fig. 2. Appropriate mesh treatment is required near surfaces to avoid overprediction of particle deposition. In fact, in the direction normal to the wall, particles might be subjected to high fluctuating velocity within the viscous sub layer resulting in increased frequency of particle-wall collision. The mesh treatment consisted of proper combination of face sizing and surface inflation (Fig. 2).

In order to compare the removal effectiveness of particles for the different configurations studied air quality indexes were introduced. First, normalized particle concentration in the occupied zone (AOC) is defined as the ratio of particle concentration in the occupied zone and particle generation concentration. The occupied zone was considered from the floor to a height of $1.2 \mathrm{~m}$ since in general for sleeping and seated occupants in addition to children the breathing level is below $1.2 \mathrm{~m}$ which constitutes a critical zone where high IAQ should be provided by reducing particle concentration. Second, the percentage of escaped particles (PEP) is defined as the ratio of number of exhausted particles to the number of generated particles which should be as high a possible to prevent accumulation of particles within the indoor environment.

\section{Results and discussion}

\subsection{Experimental Validation}

Experiments were performed to compare particle distribution in conventional MV (ventilation mode 1) and DV (ventilation mode 2) rooms. A testing chamber has been built to accommodate different ventilation configurations. The experimental room dimensions are (4.95 $\mathrm{m} \times 4.50 \mathrm{~m} \times 2.52 \mathrm{~m})$. The experimental room is characterized by a top wall $\mathrm{MV}$ inlet supplying an airflow rate of $189 \mathrm{~L} / \mathrm{s}$ at a temperature of $18^{\circ} \mathrm{C}$. Another air supply option is a floor register to simulate DV inlet delivering air at same operating conditions. Dampers controlled the opening and closing of inlets and outlets vents. The thermal load of the experimental room has several sources: roof load of $9.97 \mathrm{~W} / \mathrm{m}^{2}$, ceiling conventional lighting load of $10 \mathrm{~W} / \mathrm{m}^{2}$, and walls load of $10.96 \mathrm{~W} / \mathrm{m}^{2}$.

Validation was performed for both mixed and displaced ventilation configurations. The relative error obtained was in the order of $10 \%$ showing good agreement between the CFD model and experimental results. Therefore, the CFD model developed computes accurately particle behavior and distribution for variable ventilation configurations.

(a) MV Configuration

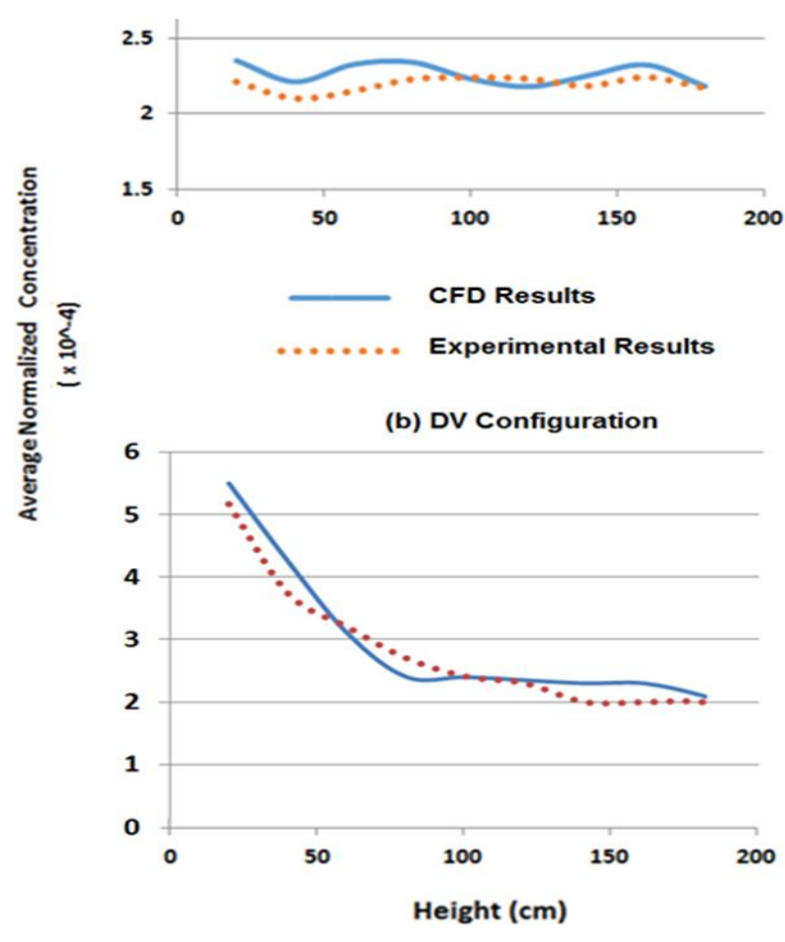

Fig. 3. Comparison of experimental and CFD results for validation of the CFD model 
Figure 3a shows the variation of averaged normalized concentration with height for the conventional MV configuration with supply and return from the top of the room while Fig. 3b represents validation for the DV system. An approximately uniform concentration was obtain for the typical MV mode (Fig. 3a) which is due to the mixing effect created by this configuration. On the other hand, a stratification effect, in the concentration variation with height, is observed for the DV mode (Fig. $3 b)$. This stratification from higher to lower concentrations when moving from the floor towards the ceiling is caused by the upward DV flow. In the occupied zone, for heights below $1.1 \mathrm{~m}$, the DV concentrations are significantly higher than the MV one representing high risks of contamination in case of particle generation from the floor level.

The validated CFD model was then adopted to perform a parametric study on spaces ventilated by MV and DV systems to assess their effectiveness in particle removal during a vacuuming session.

\subsection{Parametric Study}

Numerical CFD simulations were performed for a typical room of dimensions $(3.4 \mathrm{~m} \times 3.4 \mathrm{~m} \times 2.6 \mathrm{~m})$ for comparison of $\mathrm{MV}$ and $\mathrm{DV}$ and RDV configurations in terms of their effectiveness in removing particles generated at floor level. Particles of diameter $2.5 \mu \mathrm{m}$ were considered because fine particles are largely present in indoor spaces and their behavior is largely affected by airflow distribution while for large particles gravitational settling effect is dominant. A parametric study was conducted to investigate the effect of air flow rate by considering three typical flow rates of 50,75 and $100 \mathrm{~L} / \mathrm{s}$. Table 1 summarizes variation of average normalized particle concentration in the occupied zone (AOC) and Table 2 shows the percentage of escaped particles (PEP) for the different configurations studied.

\begin{tabular}{|l|l|l|l|}
\hline $\begin{array}{l}\text { Flow Rate } \\
(\mathrm{L} / \mathrm{s})\end{array}$ & $\mathbf{5 0}$ & $\mathbf{7 5}$ & $\mathbf{1 0 0}$ \\
\hline MV & $\mathbf{1 3 . 7 6}$ & $\mathbf{9 . 0 3}$ & $\mathbf{5 . 8 8}$ \\
\hline DV & $\mathbf{1 8 . 0 8}$ & $\mathbf{1 6 . 8 7}$ & $\mathbf{7 . 0 3}$ \\
\hline RDV1 & $\mathbf{7 . 5 9}$ & $\mathbf{4 . 7 1}$ & $\mathbf{2 . 7 9}$ \\
\hline RDV2 & $\mathbf{5 . 8 7}$ & $\mathbf{3 . 5 2}$ & $\mathbf{1 . 9 2}$ \\
\hline
\end{tabular}

Table 1. : Effect of flow rate on AOC $\left(\times 10^{-4}\right)$ for the different configurations studied

\begin{tabular}{|l|l|l|l|}
\hline $\begin{array}{l}\text { Flow Rate } \\
(\mathrm{L} / \mathrm{s})\end{array}$ & $\mathbf{5 0}$ & $\mathbf{7 5}$ & $\mathbf{1 0 0}$ \\
\hline MV & $\mathbf{2 8 . 6 4}$ & $\mathbf{4 1 . 7 6}$ & $\mathbf{4 6 . 8 7}$ \\
\hline DV & $\mathbf{1 7 . 7 2}$ & $\mathbf{2 7 . 1 3}$ & $\mathbf{3 2 . 7 6}$ \\
\hline RDV1 & $\mathbf{4 6 . 9 7}$ & $\mathbf{5 8 . 8 1}$ & $\mathbf{6 7 . 7 2}$ \\
\hline RDV2 & $\mathbf{5 6 . 9 6}$ & $\mathbf{6 7 . 8 4}$ & $\mathbf{7 5 . 3 5}$ \\
\hline
\end{tabular}

Table 2 : Effect of flow rate on PEP $\left(\times 10^{-4}\right)$ for the different configurations studied
Increased flow rate enhanced particle removal performance for all configurations studied which is shown by reduced AOC and increased PEP.

MV and DV were compared on different levels. In case of generation of particles at floor level, DV resulted in lower PEP compared to conventional MV (Table 2) and higher AOC (Table 1). This is due to the upward transport of particles generated at floor level by the supply DV jet and their distribution within the space resulting in an ineffective removal from exhaust at ceiling level because of large distance between floor generation and exhaust location. Hence, during a vacuuming session in a DV room, it is suggested to reverse the flow pattern by supplying air from ceiling and exhausting from ground level creating a suction effect at floor level contributing to particle removal and thus reducing health risks. For this reason the RDV configurations were studied in comparison with MV.

RDV provided much better performance compared to $\mathrm{DV}$ and $\mathrm{MV}$ in particle removal from the occupied space resulting in reduced AOC and increased PEP (Tables 1 and 2). Fig. 4 and Fig. 5 represent normalized concentration contours at the breathing and floor levels for MV and RDV2 respectively. A large enhancement is provided by RDV2 compared to MV resulting in much lower concentrations in the two critical planes illustrated in Figs. 4 and 5. This is due to the positive suction effect created by symmetric exhausts at floor level in RDV2 configuration where two exhausts were placed opposing each other resulting in a suction effect covering the majority of the floor area opposing the formation of high particle concentrations zones.

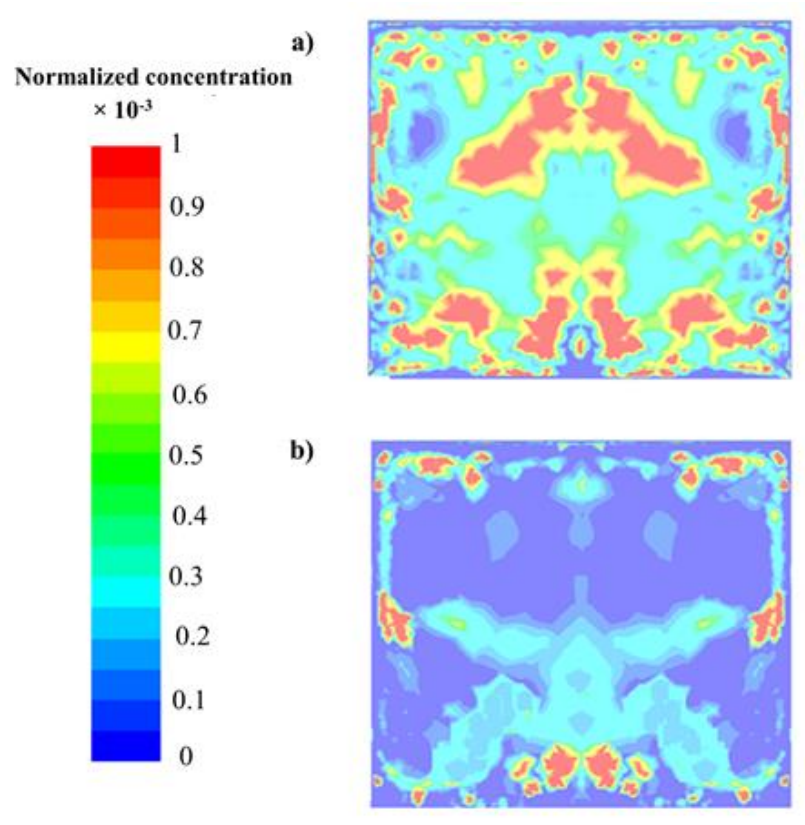

Fig. 4. Normalized concentration contours at the breathing level (height $1.1 \mathrm{~m}$ for seated occupant) for MV and RDV2 configurations 


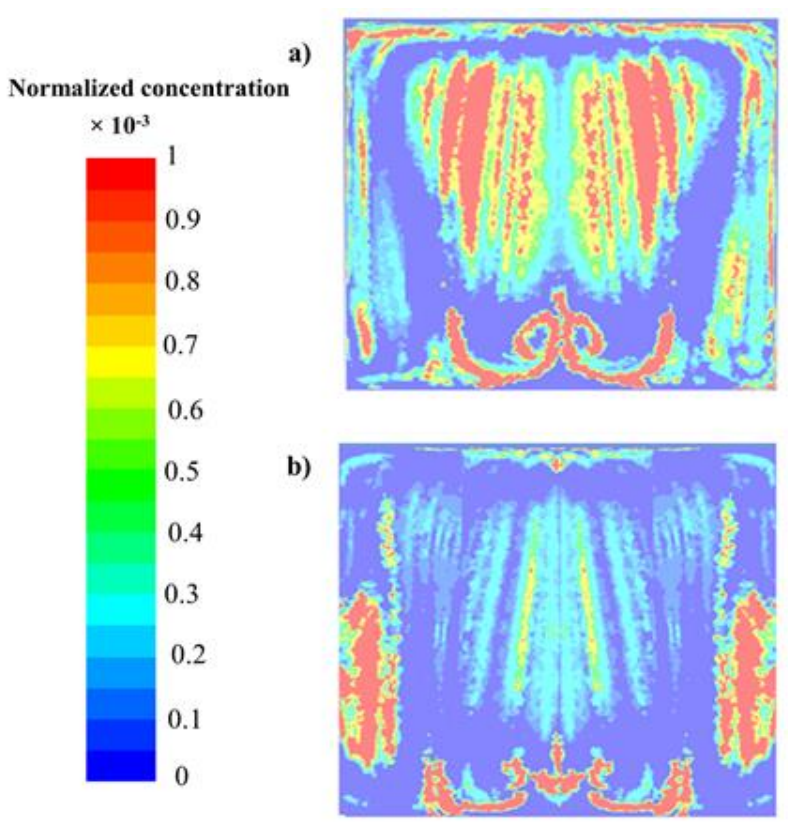

Fig. 5. Normalized concentration contours at the floor level (height $0.2 \mathrm{~m}$ ) for MV and RDV2 configurations

\section{Conclusion}

A CFD model was developed and validated experimentally to compare the effectiveness of MV and DV in the removal of re-suspended particles from floor level.

Bad performance is provided by DV compared to conventional MV leading to higher normalized concentrations within the space. This can be explained by the upward transport of particles generated at floor level by the supply DV jet and distribution within the indoor space without effective removal from exhaust at ceiling level due to the large distance separating floor generation from ceiling exhaust location. Hence, during a vacuuming session in a DV room, it is suggested to reverse the flow pattern by supplying air from ceiling and exhausting from ground level creating a suction effect at contributing to particle removal and thus reducing health risks.

Increased flow rate enhanced particle removal performance for all configurations. A large enhancement is provided by RDV2 compared to MV resulting in much lower concentrations in the two critical planes illustrated. This is due to the positive suction effect created by symmetric exhausts at floor level in RDV2 configuration where two exhausts were placed opposing each other resulting in a suction effect covering the majority of the floor area.

\section{References}

[1] Höppe, P., \& Martinac, I. (1998). Indoor climate and air quality. International journal of biometeorology, 42(1), 1-7. Lindsley WG, Green BJ, Blachere FM, Martin SB, Law BF, Jensen PA, Schafer
MP. Sampling and characterization of bioaerosols. NIOSH manual of analytical methods. 5th ed. Cincinnati (OH): National Institute for Occupational Safety and Health. 2017.

[2] Lai K, Nasir ZA, Taylor J. Bioaerosols and Hospital Infections. Aerosol Science: Technology and Applications. 2014 Feb 3:271.

[3] Cao Z, Xu F, Covaci A, Wu M, Wang H, Yu G, Wang B, Deng S, Huang J, Wang X. Distribution patterns of brominated, chlorinated, and phosphorus flame retardants with particle size in indoor and outdoor dust and implications for human exposure. Environmental science \& technology. 2014 Jul 17;48(15):8839-46.

[4] Stewart K. The resuspension of particulate material from surfaces. InSurface contamination; proceedings of a symposium held at Gatlinburg, Tennessee 1964 Jun (pp. 63-74).

[5] Mukai C, Siegel JA, Novoselac A. Impact of airflow characteristics on particle resuspension from indoor surfaces. Aerosol Science and Technology. 2009 Sep 21;43(10):1022-32.

[6] Oberoi RC, Choi JI, Edwards JR, Rosati JA, Thornburg J, Rodes CE. Human-induced particle resuspension in a room. Aerosol Science and Technology. 2010 Feb 10;44(3):216-29.

[7] Knibbs LD, He C, Duchaine C, Morawska L. Vacuum cleaner emissions as a source of indoor exposure to airborne particles and bacteria. Environmental science \& technology. 2011 Dec 7;46(1):534-42.

[8] Corsi RL, Siegel JA, Chiang C. Particle resuspension during the use of vacuum cleaners on residential carpet. Journal of Occupational and Environmental Hygiene. 2008 Apr 9;5(4):232-8.

[9] Roberts, J. W., D. E. Camann, and T. M. Spittler. "Reducing lead exposure from remodeling and soil track-in in older homes." A AND WMA ANNUAL MEETING. Vol. 15. AIR \& WASTE MANAGEMENT ASSOCIATION, 1993.

[10] A.R. Ferro, R.J. Kopperud, L.M. Hildemann. Source strengths for indoor human activities that resuspend particulate matter. Environmental Science \& Technology, 38 (2004), pp. 1759-1764.

[11] Nazaroff WW. Indoor particle dynamics. Indoor air. 2004 Aug 1;14:175-83.

[12] Wallace L. Indoor particles: a review. Journal of the Air \& Waste Management Association. 1996 Feb 1;46(2):98-126.

[13] Chung KC, Hsu SP. Effect of ventilation pattern on room air and contaminant distribution. Building and Environment. 2001 Nov 1;36(9):989-98.

[14] Holmberg S, Li Y. Modelling of the indoor environment-particle dispersion and deposition. Indoor air. 1998 Jun;8(2):113-22.

[15] Todorovic, M., et al. Natural and mixed ventilation design via CFD and architectural modelling. International Journal of Ventilation 5.4 (2007): 447-458. [16] Brohus H, Knudsen HN, Nielsen PV, Clausen G, Fanger PO. Perceived air quality in a displacement 
ventilated room. Indoor Air. Proceedings of the 7th Int. Conf. on Indoor Air Quality and Climate, Nagoya, Japan 1996; 1: 811-816.

[17] Lin Z, Chow TT, Fong KF, Tsang CF, Wang Q. Comparison of performances of displacement and mixing ventilations. Part II: indoor air quality. International journal of refrigeration. 2005 Mar 1;28(2):288-305.

[18] Zhang, Z., and Q. Chen. "Experimental measurements and numerical simulations of particle transport and distribution in ventilated rooms." Atmospheric environment 40.18 (2006): 3396-3408.

[19] Brohus H, Nielsen PV. Personal exposure in displacement ventilated rooms. Indoor Air. 1996 Sep;6(3):157-67.

[20] Habchi C, Ghali K, Ghaddar N. A simplified mathematical model for predicting cross contamination in displacement ventilation air-conditioned spaces. Journal of Aerosol Science. 2014 Oct 1;76:72-86.

[21] Chen Q. Ventilation performance prediction for buildings: A method overview and recent applications. Building and environment. 2009 Apr 1;44(4):848-58.

[22] Zhang Z., Q. Chen, Prediction of particle deposition onto indoor surfaces by CFD with a modified Lagrangian method, Atmospheric Environment 43 (2009) 319-328.

[23] ANSYS Software: ANSYS Inc. http://www.ansys.com/

[24] Makhoul A, Ghali K, Ghaddar N. Investigation of Particle Transport in Offices Equipped with CeilingMounted Personalized Ventilators. Building and Environment 2013; 63: 97-107.

[25] Zhai ZJ, Zhang Z, Zhang W, Chen QY. Evaluation of various turbulence models in predicting airflow and turbulence in enclosed environments by CFD: Part $1-$ Summary of prevalent turbulence models. Hvac\&R Research. 2007 Nov 1;13(6):853-70.

[26] Hoff SJ, Janni KA, Jacobson LD. Threedimensional buoyant turbulent flows in a scaled model, slot-ventilated, livestock confinement facility. Transactions of the ASAE. 1992;35(2):671-86.

[27] Alvin C.K. Lai, F.Z. Chen, Comparison of a new Eulerian model with a modified Lagrangian approach for particle distribution and deposition indoors, Atmospheric Environment 41 (2007) 5249-5256.

[28] Li A, Ahmadi G. Dispersion and deposition of spherical particles from point sources in a turbulent channel flow. Aerosol Science and Technology 1992; 16: 209-226.

[29] Wang M, Lin CH, Chen Q. Advanced turbulence models for predicting particle transport in enclosed environments. Building and Environment 2012; 47: 40-49. [30] Hinds WC. Aerosol Technology: Properties, Behavior, and Measurement of Airborne Particles. Wiley, New York; 1982. 